\title{
CONHECIMENTOS POPULARES E EDUCAÇÃO EM SAÚDE NA FORMAÇÃO DO ENFERMEIRO*
}

Maria de Lourdes Denardin Budó** Rosita Saupe***

\section{Resumo}

$\mathrm{Na}$ perspectiva da incorporação da reforma sanitária nos projetos pedagógicos dos cursos de enfermagem, conforme as diretrizes curriculares, contextualiza a formação do enfermeiro para a educação em saúde, a importância da aproximação das práticas de cuidados e traz resultados de pesquisa com enfermeiras de sete municípios de comunidades rurais do Rio Grande do Sul. Trata-se de pesquisa qualitativa com coleta de dados através de observação participante, entrevista e análise documental, sendo os mesmos analisados em seu conteúdo. Estes dados constituem atividades observadas no trabalho das enfermeiras, na educação em saúde. Conclui que o trabalho das enfermeiras era impregnado de ações educativas, na modalidade coletiva e individual. Por outro lado, referem falta de preparo, na graduação, para melhor desempenhar esta função.

Descritores: educação em saúde; saúde da família; cultura

\section{Abstract}

From the point of view of including the health reform in the pedagogical projects of nursing courses, in accordance with curriculum guidelines, it contextualises the formation of a nurse for health education and the importance of bringing practice and care together, as well as includes the results of research with nurses in seven towns in rural communities in the state of Rio Grande do Sul. It is a qualitative survey with data collection by means of participatory observation, interviews, and document-based content analysis. These data were obtained in activities observed in the work of nurses in health education. It concludes that the work of nurses was full of educational actions, both collective and individual ones. On the other hand, undergraduate courses do not sufficiently prepare students to perform this role.

Descriptors: health education; family health; culture

Title: Popular knowledge and health education in the capacitation of a nurse

\section{Resumen}

Dentro del prisma de la incorporación de la reforma sanitaria en los proyectos pedagógicos de los cursos de enfermería, conforme las directrices curriculares, el estudio contextualiza la formación del enfermero para la educación en salud; muestra la importancia en aproximar las prácticas de cuidados y trae los resultados de una investigación con enfermeras de siete municipios de comunidades rurales de Rio Grande do Sul. Se trata de una investigación cualitativa que recoge los datos, a través de la observación participante, entrevista y análisis documental, para luego analizarlos en su contenido. Estos datos están constituidos por las actividades observadas en el trabajo de las enfermeras, en la educación en salud. Se concluye que el trabajo de las enfermeras estaba impregnado de acciones educativas, en la modalidad colectiva e individual. Por otro lado, dichas acciones denotan falta de preparación en el curso de graduación, para desempeñar mejor esta función.

Descriptores: educación en salud; salud de la familia; cultura

Titulo: Conocimientos populares y educación en salud en la formación del enfermero

\section{Introdução}

As práticas educativas em saúde têm tido uma presença marcante na atuação dos enfermeiros nas últimas décadas. Isto tem sido referenciado por diferentes autores da área ${ }^{(1-3)}$ Esta forma de atuação tem sido também uma preocupação daqueles enfermeiros que discutem e trabalham com a temática de educação, pois, o enfermeiro, além de suas funções na educação formal e informal (na formação de profissionais de saúde), desempenha atribuições na educação não formal, que inclui todas as atividades de educação e saúde individual e coletiva aos usuários dos serviços de saúde.

Referendando esta prática, verificamos a inclusão do ensino da enfermagem como área de atuação do enfermeiro nas Diretrizes Curriculares Nacionais do Curso de Graduação em Enfermagem ${ }^{(4)}$, proposta presente nas diferentes versões discutidas ao longo destes anos nos Seminários Nacionais de Diretrizes para a Educação em Enfermagem no Brasil (SENADENs). Este documento destaca que o preparo do enfermeiro para o ensino deve incluir "conteúdos pertinentes à capacitação pedagógica do enfermeiro, independente da Licenciatura em Enfermagem"(4:4). Além disto, dentre as competências previstas está a de "planejar e implementar programas de educação e promoção à saúde, considerando a especificidade dos diferentes grupos sociais e dos distintos processos de vida, saúde, trabalho e adoecimento"(4:3).

Mesmo com toda esta preocupação em atingir a educação das pessoas visando um cuidado adequado e que leve a uma melhor qualidade de vida, as práticas educativas em saúde "não conseguem, por via de regra, gerar grandes transformações, que tenham impacto no modo de vida da população, em suas condições de saúde e na construção de sua cidadania"(3:63).

Neste trabalho tem-se a intenção de discutir esta temática, de fundamental importância para a nossa atuação como enfermeiros, buscando em alguns referencias teóricos a fundamentação para uma formação do enfermeiro educador que transite nas teorias pedagógicas e de enfermagem e que leve a uma aproximação dos conhecimentos do sistema profissional e popular de cuidados, tendo como fundamentação uma abordagem cultural do cuidado. Somando-se a isto trazemos dados empíricos de uma pesquisa realizada com enfermeiras que atuam em unidades básicas de saúde na Quarta Colônia de Imigração Italiana do Rio Grande do Sul (RS).

\section{A formação dos enfermeiros para a educação em Saúde no Brasil}

Apesar de entender-se que a enfermagem é tão antiga como é a humanidade, propõe-se neste momento deixar de lado todo este percurso histórico, para ater-se em um recorte breve daquilo que foi preconizado como o Sistema Nightingale para formação dos enfermeiros, quer em nível mundial ou nacional. Isto não significa que as demais iniciativas da formação destes profissionais não tiveram a merecida importância na história de nossa profissão, influenciando sobremaneira a prática atual. Trata-se, neste momento, de uma análise da formação do enfermeiro na perspectiva de seu papel

\footnotetext{
* Texto construído a partir de: Budó MLD. A prática de cuidados em comunidades rurais e o preparo da enfermeira [tese de doutorado em enfermagem]. Florianópolis (SC): Pós-Graduação em Enfermagem, Universidade Federal de Santa Catarina;2000.201f. **Enfermeira. Doutora em Filosofia da Enfermagem - UFSC. Professora adjunto do Departamento de Enfermagem da UFSM. ***Enfermeira. Doutora em Enfermagem - USP. Professora da Pós-graduação em Saúde - UNIVALI. Linha de Pesquisa: Promoção e Educação em Saúde.

E-mail do autor: lourdesd@infoway.com.br
} 
social e cultural, aspectos que se considera fundamentais para trabalhar com as pessoas.

A enfermagem moderna nasce com Florence Nightingale, com a institucionalização da profissão, e a criação da primeira escola de enfermagem nos moldes por ela preconizados, em 1860, no Hospital St. Thomas, na Inglaterra. A tônica dessa escola era a formação de profissionais de forma criteriosa, sendo que a disciplina e a conduta moral eram requisitos primordiais. Isto se deve, especialmente, ao fato de que a enfermagem, na época, contava com profissionais de duvidosa conduta moral. Florence estabelece alguns critérios para o que passou a ser o Sistema Nightingale, dentre eles a rigorosa seleção de candidatas, a direção de escolas por enfermeiras, e ensino teórico e prático metódicos. Este sistema foi, com o passar do tempo, adequando-se às culturas, modos e costumes de vida dos países para onde foi sendo importado sendo que, atualmente, talvez tenhamos tantos modelos quanto as nações nas quais o Sistema Nightingale foi implantado(5).

O Sistema Nightingale, criado no século XIX, na Inglaterra é difundido por todo o mundo e chega também ao Brasil, em 1923, com a criação da Escola de Enfermeiras do Departamento Nacional de Saúde Pública, que passou, em 1926, a se chamar Escola de Enfermeiras D. Anna Nery ${ }^{(6)}$. No Brasil, este modelo é introduzido a partir da necessidade da formação de um tipo de profissional para trabalhar no precário sistema de saúde brasileiro da época. No início do século, a urbanização crescente das cidades, a falta de planejamento e saneamento básico, fez com que se disseminassem as doenças pestilenciais e de massa, o que criou sérios constrangimentos à política econômica brasileira. Frente a estes problemas, é criado o Departamento Nacional de Saúde Pública (DNSP), assumindo a sua direção Carlos Chagas que, em 1921, visita os Estados Unidos e conhece as enfermeiras nightingale, acredita ser este o profissional de saúde necessário para atender à estratégia sanitarista governamental(6).

Através da ajuda financeira da Fundação Rockfeller, chegam ao Brasil as primeiras enfermeiras americanas, lideradas por Ethel Parsons, com o objetivo de avaliar a situação e planejar a organização de um serviço de enfermagem. Nasce, com isso, a moderna enfermagem brasileira, atendendo mais a uma medida do governo do que a um consenso nacional(7).

No contexto da criação da enfermagem de Saúde Pública no Brasil, Ethel Parsons propõe a formação imediata de visitadoras sanitárias, para exercer a vigilância em domicílios sobre casos de tuberculose, e a criação de uma Escola de Enfermeiras. A partir de 1926, com a formação das enfermeiras diplomadas pela Escola Anna Nery, as visitadoras foram sendo substituídas por estas novas profissionais e, "no final de 1927, o Serviço de Enfermeiras ia aproximando-se do ideal e encaminhando-se para o que se podia entender por um Serviço de Enfermeiras de Saúde Pública generalizado" (8:30). A atribuição das enfermeiras de Saúde Pública, era "a responsabilidade pela vigilância e notificações, pelo cuidado aos doentes e às famílias, pelo ensino e orientação à comunidade" (8:30). A reflexão sobre estes fatos históricos, em contraponto ao que é hoje preconizado como mudança do modelo de atenção à saúde, que tem no Sistema Único de Saúde (SUS) seus princípios e programas operacionais, em especial a Estratégia de Saúde da Família (ESF), a orientação político social determinante, evidencia, com extrema clareza, o espírito precursor das lideranças da época, notadamente dos enfermeiros.

Por outro lado, a partir destes dados é possível perceber que a chamada moderna profissão de enfermagem nasce para dar conta dos problemas enfrentados pelo governo no sentido de resolver suas questões mais econômicas do que de saúde. Mas também nasce voltada para a saúde pública e nesta, vinculada especialmente ao cuidado, no qual se inclui o ensino e orientação às pessoas. Todavia, o ensino da enfermagem não seguiu propriamente este caminho, pois em seu desenvolvimento foi priorizando a enfermagem curativa e hospitalocêntrica exigida pelo complexo médico-hospitalar, abdicando da ênfase em promoção e educação em saúde que fundamentou suas origens ${ }^{(9)}$.

$\mathrm{Na}$ atualidade há todo um empenho e determinação no sentido do preparo do enfermeiro para trabalhar com as populações, em busca da implementação da Reforma Sanitária, representada atualmente pelo Sistema Único de Saúde. Parte deste empenho concentra-se na necessidade da formação de enfermeiros que estejam preparados para a educação, como demonstra determinada pesquisa, que teve como objetivo conhecer a realidade do preparo do enfermeiro para desempenhar seu papel de educador e apontar as possibilidades embutidas nesta realidade ${ }^{(1)}$.

Com este trabalho ficou evidente que, apesar da necessidade sentida pelo enfermeiro em trabalhar na educação, não tem havido uma formação adequada para a necessidade sentida. Com a nova legislação para a elaboração dos novos currículos de enfermagem e seus Projetos Político Pedagógico, há uma crescente preocupação em explicitar as competências a serem adquiridas através de conhecimentos, habilidades e atitudes, que contemplem este preparo.

\section{A integração das práticas de cuidado na educação em saúde}

Hoje, ao pensarmos a formação dos enfermeiros, entendemos que os profissionais que trabalham com pessoas e que têm preocupação com a melhoria da qualidade de suas vidas necessitam de uma abordagem adequada, a fim de que possam atingi-las em sua plenitude. Para isso, torna-se de fundamental importância a busca criativa de novas alternativas para o trabalho, associando saúde e educação das populações, num intercâmbio constante entre o saber desenvolvido no viver diário e o oriundo do meio acadêmico, inseridos em um contexto histórico, político, social, econômico e cultural.

As práticas educativas são uma constante na vivência dos profissionais da saúde, dentre eles a do enfermeiro, cuja essência tem sido apontada por grupos de profissionais, como sendo o cuidado. O cuidado envolve todo um conjunto de práticas, entre as quais a educação é um de seus elementos fundamentais. Cuidar passa a ser muito mais do que fazer, ajudar ou orientar dentro do nosso saber acadêmico técnicocientífico. Trabalhamos com pessoas que possuem um referencial de vida marcado pela visão de mundo, crenças e valores de uma cultura, que as orientou em todos os momentos e que, na situação de crise, procuram um serviço de saúde e passam a ser pacientes tratados uniformemente, como se todos fossem iguais, através dos padrões gerais de atendimento à saúde e à universalização de sintomas e patologias. Nesta situação, o saber popular é negado e imposto um conhecimento e prescrição fundamentados no modelo técnico-científico, próprio da academia, e que, ainda hoje, é centrado na doença, no modelo biomédico, embora alguns avanços estejam acontecendo, principalmente frente aos trabalhos oriundos de pesquisas, dissertações e teses dos programas de pósgraduação das Instituições de Ensino Superior (IES). Considerar também a dimensão sócio-cultural da saúde é fundamental, a fim de que tenhamos a possibilidade de abrangência suficiente para atingirmos as pessoas. Isto porque há uma estreita relação entre as crenças, valores, costumes que são desenvolvidos no cotidiano pelas pessoas e a forma como elas se expressam nas situações de saúde-doença.

Portanto, para trabalhar na prática, num contexto de educação e saúde, torna-se fundamental que se estabeleça uma relação entre os conhecimentos das diferentes ciências que compõem a saúde e as ciências sociais e de educação, num comprometimento com o movimento social, com a democracia, com o respeito pela liberdade individual, na participação no processo de conscientização. Para isto, é 
necessária uma concepção de saúde que ultrapasse aspectos do modelo biomédico, numa visão ampliada pelos diferentes aspectos das ciências sociais, como a apresentada nas sete teses sobre a educação sanitária para a participação comunitária(10) $^{(10)}$ Neste artigo são postulados dois princípios de trabalho: é necessário conhecer e contar com o ser humano, os quais se expressam em duas premissas: "somente conhecendo o indivíduo e sua circunstância de vida é possível uma ação eficiente e permanente em saúde; e nada pode mudar a saúde do outro, se este não quer fazê-lo por si mesmo"(10:7). Com este enfoque, não há como trabalhar em educação na saúde sem conhecer o ser humano em suas diferentes dimensões, no seu contexto de vida.

Nas três últimas décadas tem havido um crescimento daquilo que emergiu como sendo o cuidado de enfermagem, numa visão mais ampla e integrada. Dentre os trabalhos desta vertente há a abordagem sobre o campo de competência dos cuidados, na qual é proposto um processo de cuidados de enfermagem. Este processo é referido como o encontro entre duas ou mais pessoas, sendo que cada uma detém elementos deste processo de cuidados, que se situa na

encruzilhada de um sistema de troca, proveniente de origens diferentes e complementares, com vista a conseguir determinar a natureza dos cuidados a proporcionar, a razão destes cuidados, os objetivos e os meios necessários para os atingiri(11:293).

Nesta situação, o cuidado de enfermagem torna-se, assim, um processo entre parceiros sociais, com competências diferentes e complementares, utilizando as capacidades e recursos de cada um, no ambiente que acontecer, seja no domicílio ou instituição de saúde. Para isso, é proposta a utilização de um processo que permite uma abordagem global situando a pessoa no seu contexto de vida, numa tentativa de compreendê-la em relação aos seus costumes, hábitos de vida, crenças, valores, bem como situar o impacto da doença e das suas limitações em relação a este contexto. Isto também ocorre quando se dá a educação em saúde, pois quando adentramos numa situação e projetamos os nossos conhecimentos, sem antes informarmo-nos da situação, geralmente teremos uma conduta inadequada ${ }^{(11)}$.

$\mathrm{Na}$ atualidade, a Teoria da Diversidade e Universalidade do Cuidado Cultural ${ }^{(12,13)}$ tem influenciado toda uma geração de autores e pesquisadores na área de enfermagem. Neste trabalho tem sido defendida a importância do desenvolvimento de estudos sobre o cuidado humano, para que elementos culturais comuns e diversificados possam ser conhecidos, proporcionando o crescimento da enfermagem como disciplina.

Vimos, até aqui, que a prática de cuidado na enfermagem tem sido questionada, nos últimos anos, ao mesmo tempo em que autores têm proposto algumas alternativas de crescimento do saber na enfermagem. Podemos afirmar que vivemos hoje um momento muito fértil, no qual tem sido possível trazer para a comunidade acadêmica as discussões, pontos de vista, que têm contribuído de forma fundamental para a compreensão da prática, da teoria e pesquisa de enfermagem.

O fenômeno cuidado tem representado, especialmente na área de enfermagem , a produção de uma vasta literatura, especialmente desenvolvida nas últimas décadas, que o tem colocado como o seu foco central, a sua essência, o seu domínio unificador. Mas o cuidado em si não é prerrogativa exclusiva das profissões, até porque ele se encontra na vida das pessoas, independente de qualquer envolvimento com saber organizado e instituído por uma ou outra profissão. Revisando a trajetória histórica da humanidade, pode-se reconhecer que o saber contido nas diferentes áreas do conhecimento, antes de ser parte da academia, seguiu caminhos e se firmou como conhecimento popular. A área da saúde especialmente tem seu nascimento nas práticas cotidianas, que aos poucos foi sendo absorvida pelo saber científico, sofisticando-se com a inserção do aparato tecnológico. Mesmo nos dias atuais, em algumas situações, os cientistas retornam ao saber popular e tradicional estabelecendo trocas, mas muitas vezes distanciando-se de suas origens.

Nos últimos tempos, alguns autores ${ }^{(2,12,14)}$ na área da enfermagem, têm se voltado ao trabalho de valorização do saber popular, destacando a importância de conhecer-se as culturas para haver a possibilidade de maior integração das pessoas cuidadas nas atividades de cuidados em saúde. Muitos estudos que utilizaram a Pedagogia Freireana(15), na área de enfermagem, também partem do conhecimento popular e da cultura, com pessoas que estão vivenciando problemas ou situações existenciais semelhantes. Da comunhão destas pessoas surge um grupo especial, denominado de Círculo de Cultura. No Brasil, em algumas dissertações de mestrado os enfermeiros propõem o Círculo de Cultura, colocando-se como animadores destes grupos ${ }^{(15)}$

Por isso, acredita-se que integrar os conhecimentos oriundos do saber popular aos do saber profissional é o grande desafio da enfermagem atual. Isto não significa que o saber profissional vai absorver tudo que vem do saber popular, significa criar uma ponte de integração, de entendimento, onde se busca conhecer o que se passa na vida cotidiana das pessoas cuidadas, resgatando e respeitando um saber que teve uma trajetória histórica. Por trás de um cuidado inadequado apresentado por alguma pessoa, há uma simbologia que representa os valores, crenças, a visão de mundo no modo de vida que a tradição familiar referendou. Se não trabalharmos esta nuance, permeada de valores culturais, poderemos ver sem sucesso nosso trabalho, notadamente na educação em saúde.

Em nosso entendimento, mesmo sem unanimidade ou total clareza, parece existir, na vivência profissional, a valorização do cuidado, incluindo a educação em saúde e a relação com as pessoas, para a realização pessoal e profissional. Considerar o cotidiano das pessoas, seus modos de vida, as formas de enfrentamento do adoecimento e de comemoração da saúde e da vida é que precisam ser buscadas e incorporadas ao processo de cuidar e educar em saúde.

Sendo assim, o cuidado profissional a ser trabalhado pela enfermagem deve ter alguns parâmetros para proporcionar uma atuação da cuidadora profissional numa forma de ação que venha a atingir as pessoas cuidadas naquilo de que mais precisam, valorizando suas vivências, respeitando seu saber. Assim, o preparo do enfermeiro se torna o elemento fundamental a fim de que as abordagens sejam centro de reflexão crítica e se busquem outras formas para trabalhar a educação da cuidadora profissional.

E um dos grandes desafios da atualidade para os educadores constitui-se em articular igualdade e diferença, a base cultural comum e expressões de pluralidade social e cultural. A idéia de globalização na qual as fronteiras culturais seriam derrubadas e que todos faríamos parte de um mundo como cidadãos planetários, com linguagens gerais, homogeneizadas e as expressões particulares seriam extintas pela imposição cultural não tem sido comprovado pelos estudos recentes ${ }^{(16)}$. As peculiaridades de cada cultura e as multiculturas presentes em cada comunidade nos têm apontado possibilidades e elementos que fundamentam esta reflexão.

Em comunidades rurais são destacas situações nas quais as pessoas participantes da pesquisa, quando se referem ao cuidado em saúde desenvolvido nas famílias, apontavam diferenças entre vizinhos ou famílias do marido ou esposa, como isto é diferente dos costumes lá da minha família, demonstrando uma tendência a não uniformização do cuidado cultural, mas numa perspectiva multicultural, mesmo em comunidades tidas como de uma mesma cultura ${ }^{(17)}$. 


\section{A educação em saúde na prática das enfermeiras da $4^{a}$ colônia de imigração italiana, RS}

Os dados a seguir apresentados fazem parte de uma pesquisa $^{(18)}$ realizada com enfermeiras nos municípios da $4^{\mathrm{a}}$ Colônia de Imigração Italiana, do Rio Grande do Sul: Dona Francisca, Faxinal do Soturno, Ivorá, Nova Palma, Pinhal Grande, São João do Polêsine e Silveira Martins. Considerando-se a proposta de pesquisa, seus objetivos e questões, optou-se por utilizar-se a análise documental, a observação participante e a entrevista, técnicas importantes para fornecer os dados necessários para análise. Foram integrados estes três métodos de coleta, visando a convergência dos dados, através de uma triangulação de métodos ${ }^{(19)}$. Antes do início da coleta de dados, foi explicada a finalidade da pesquisa, a metodologia a ser utilizada, assegurando o anonimato, o sigilo e a livre participação, bem como obtida a autorização de gravação das entrevistas. Além disso, foi apresentado o Termo de Consentimento Livre e Esclarecido(20).

Neste estudo, foram utilizadas algumas categorias de análise das atividades das enfermeiras que atuam nas unidades básicas de saúde da região, já pré-estabelecidas, de acordo com os conceitos da pesquisa: comunidade rural, cuidado de enfermagem e preparo da enfermeira. Os dados apresentados neste artigo se referem ao conceito cuidado de enfermagem, na categoria cuidando do ser humano, que constituem as atividades observadas no trabalho das enfermeiras, no que se refere à educação em saúde.

Foi utilizada a análise de conteúdo, a fim de atingir os significados manifestos e latentes. Constituída de três fases de análise temática: a pré-análise, a exploração do material e o tratamento dos resultados obtidos e interpretação(21).

\subsection{A educação em saúde}

O processo de trabalho da enfermeira em seu dia a dia encontrava-se impregnado de ações educativas. Quase a totalidade de suas ações consistia de algum tipo de orientação, quer seja na realização de procedimentos ou nas ações educativas propriamente ditas. Em todos os momentos em que um cliente se aproximava da enfermeira havia alguma fala orientadora, a indicação de formas de cuidados ou mesmo uma prescrição pré-estabelecida, como aquelas que fazem parte dos cuidados com as vacinas. As formas observadas incluíam trabalho coletivo e individual.

As ações educativas coletivas compreendiam reuniões e cursos para grupos específicos como: de terceira idade, de gestantes, de hipertensos, de trabalhadores rurais, de alcoólicos anônimos, de escolares, de adolescentes e de grupos heterogêneos, como os que se encontravam na sala de espera para consultas.

Todos os municípios possuem grupos de terceira idade organizados, sendo que a maioria deles é mantido por associação própria, com diretoria, que realiza as programações com a participação direta ou indireta da secretaria de saúde de cada município, na qual a enfermeira tem algum tipo de participação. Em algumas situações é convidada a participar como responsável técnica ou palestrante das reuniões. No geral, ao término da palestra, é verificada a pressão arterial pela enfermeira e/ou auxiliar de enfermagem. Nestas oportunidades, o momento de encontro é aproveitado para que conteúdos importantes sejam transmitidos às pessoas presentes. Uma das enfermeiras relata como é organizado o encontro, no seu município:

o grupo de idosos compreende duas turmas na zona urbana [...]. Nesse grupo eu sou a responsável técnica [...] tem o professor de educação física, que faz a atividade física em todas as aulas e a secretária de saúde que sempre vai junto comigo [...]. Primeiro a gente conversa, das duas às três e meia a gente fica conversando com eles, ou faço palestras, ou expressão corporal através de teatro, ou as oficinas, ou deixo livre, porque uma vez por mês eles têm liberdade para fazer o que quiserem, um bingo, ou jogando cartas, se eles quiserem ficam a tarde inteira jogando cartas. Se quiserem ficar só jogando conversa fora, mas os outros três encontros do mês é organização minha [...]. Sou eu quem programo as atividades ou os temas a serem abordados, segundo o que vou sentindo ser necessário (D1).

Os grupos de gestantes estão presentes em quatro dos sete municípios, sendo que um deles já teve o grupo, mas atualmente não possui profissionais para mantê-lo funcionando. As orientações são feitas pela (o) enfermeiro, na sala de espera ou individualmente, como pode ser visto na seguinte fala:

nós tínhamos o grupo de gestantes, funcionou um tempo [...] fiquei com a orientação mais a nível de sala de espera ou na hora que ela vem fazer a ficha para consultar, o pré-natal, é feita a orientação dos cuidados, todas as gestantes, principalmente as carentes, recebem exames, ultra-som, medicação, elas têm uma carteirinha própria da gestante. E com a gestante este grupo terminou até por falta de recursos humanos, se tivesse uma enfermeira só para isso, com certeza nós teríamos todos os grupos funcionando, também o grupo de hipertensos, o grupo de diabete, nós tínhamos todos estes grupos [...] a orientação é feita individual e não no grupo, a gente orienta quanto à alimentação, quanto à hidratação, quanto à dieta, principalmente (D2).

A sala de espera é outro momento utilizado pelas enfermeiras para trabalhar temas de educação em saúde, como hipertensão arterial, cuidados com a alimentação, alcoolismo, tabagismo, entre outros temas, como na situação em que a enfermeira relata:

a gente orienta as pessoas sobre alimentação, sobre doenças, a gente explica, agora na época do inverno de como agasalhar, de como cuidar da saúde, da higiene, a gente pega aquelas crianças que se penduram nos carros e se acidentam, então a gente acaba falando [...] (D3).

A educação em saúde era também realizada de forma individual, fazendo parte de todas as ações da enfermeira. No geral, quando um cliente é cuidado pela enfermeira, quer seja na aplicação de vacinas, na entrega de resultado de exames, de medicamentos na farmácia do Posto ou na coleta de material para exame de preventivo de câncer de colo uterino, recebe algum tipo de orientação. Todo o momento de contato com o cliente é aproveitado para fazer as orientações indispensáveis a cada caso, como nas situações a seguir, na qual a enfermeira orienta sobre o auto-exame de mamas:

A enfermeira explicava para a mulher que fazia o exame preventivo de câncer: vou te dar uma folhinha e mostrar como se faz. Se tu achares algo anormal, tens que vir no posto. Orientou para tirar as roupas para o exame. A mulher sentou na mesa e ela postou-se na sua frente e disse:

Faz de conta que eu sou o teu espelho [...] É normal as mamas serem um pouco diferentes uma da outra, mas para isso tu precisas olhar todo o mês, porque então tu vais te conhecer e identificar logo se houver alguma diferença [...] Não pode ter algo que não tinha antes.

Diz para que ela deite e demonstra a palpação, dizendo:

Tem que tocar toda a mama procurando algum carocinho, alguma região mais endurecida. Por último, tu apertas para ver se sai alguma secreção. Na hora do banho é melhor, porque a mão desliza [...] (D3).

Em pesquisa(1) realizada com professores, alunos e egressos de diversos cursos de enfermagem, no Brasil, foi constada a importância do preparo do enfermeiro para ser educador e que esta função está presente em todas as áreas de sua atuação. Entre os egressos dos cursos estudados, a opinião referenda este achado e assinala a falta de preparo para este importante papel. 
Assim, educação em saúde aparece como a primeira e mais fortemente área focalizada pelos entrevistados ao reportar o papel educativo da enfermeira. Por outro lado,

ao discorrerem sobre esta dimensão, poucos conseguem ultrapassar as tradicionais ações de orientação e palestras. Mas, outras posturas já começam a aparecer colocando como pobreza profissional o entendimento que reduz a educação em saúde a estas duas atividades $^{(1: 29)}$.

Esta constatação vem confirmar o que tem sido observado e expresso pelas enfermeiras que atuam na Quarta Colônia de Imigração Italiana do RS, que têm sentido esta importância, frente às necessidades enfrentadas pelo tipo de trabalho que desenvolvem. Por outro lado, referem a falta de preparo, durante a graduação, para que possam melhor desempenhar esta função.

\section{Considerações finais}

As ações de educação em saúde parecem estar definitivamente incorporadas ao processo de trabalho dos enfermeiros brasileiros: a sua história aponta para esta afirmação e os dados da investigação apresentada confirmam esta tendência. Todavia, no momento atual de consolidação da Reforma Sanitária e implantação das Diretrizes Curriculares, na perspectiva do SÚS, é preciso revisitar esta história, confirmar seus acertos, descobrir seus estrangulamentos e propor formas inovadoras que possam ser implantadas e testadas. Pretendemos colaborar nesta perspectiva.

Assim, como acerto evidenciamos o empenho dos enfermeiros em implementar programas de saúde que têm como eixo condutor a educação em saúde, seja na sua versão individual ou coletiva; como estrangulamento detectamos a dificuldade dos profissionais em acreditarem realmente nos seres humanos com os quais interagem, em sua capacidade de aprender e de administrar a própria vida; como proposta colocamos a integração entre conhecimento profissional e saber popular como metodologia orientadora tanto do processo de educação na saúde como dos programas de educação em saúde.

Como reflexão final ponderamos que a educação em saúde tem crescido pela instrumentalização originária das teorias e métodos da educação geral. Neste artigo, mesmo na consideração da importância destas contribuições, evidenciamos outra perspectiva, qual seja, a da fundamentação de propostas que têm como referencial o conhecimento gerado na própria profissão e divulgado em suas teorias de sustentação.

\section{Referências}

1. Saupe R, organizadora. Preparo do enfermeiro para ser educador: realidade e possibilidades. Florianópolis (SC), UFSC; 1999. [69 p] Disponível em: URL: <http://www.ufsc.br/enfermagem/educacao. htm>. Acessado em: 7 abr 2003.

2. Budó MLD. A prática de cuidados em comunidades rurais e o preparo da enfermeira [tese de Doutorado em Enfermagem]. Florianópolis (SC): Pós-Graduação em Enfermagem, Universidade Federal de Santa Catarina;2000.201f.

3. Cocco MIM. Práticas educativas em saúde e a construção do conhecimento emancipatório. In: Bagnato MHS, Cocco MIM, Sord MRL, organizadores. Educação, saúde e trabalho: antigos problemas, novos contextos, outros olhares. Campinas (SP): Alínea; 1999. 132 p.63-70p.
4. Ministério da Educação (BR). Conselho Nacional de Educação. Câmara de Educação Superior. Resolução CNE/CES N. 3, de 7 de novembro de 2001. Brasília (DF); 2001. [5 p.] Disponível em: URL:<http://www. mec.gov.br/sesu/ftp/resolucao/0301Enfermagem.doc $>$. Acessado em: 22 jul 2003.

5. Saupe R. Ação e reflexão na formação do enfermeiro através dos tempos. In: Saupe R, organizadora. Educação em enfermagem: da realidade construída à possibilidade em construção. Florianópolis (SC): Editora da UFSC;1998.271p.p.28-73.

6. Pires DP. Hegemonia médica na saúde e a enfermagem: Brasil 1500 a 1930. São Paulo: Cortez;1989.155p.

7. Melo C. Divisão social do trabalho e enfermagem. São Paulo: Cortez; 1986.94p.

8. Carvalho V. A enfermagem de saúde pública como prática social: um ponto de vista sobre a formação da enfermeira em nível de graduação. Esc Anna Nery Rev Enferm, Rio de Janeiro 1997 jul; 1(n. esp): 25-41.

9. Almeida MCP, Rocha JSY. O Saber da Enfermagem e sua Dimensão Prática. São Paulo: Cortez;1986.p159.

10. Briceño-León $\mathrm{R}$. Siete Tesis sobre la educación sanitaria para la participación comunitaria. Cadernos de Saúde Pública, Rio de Janeiro, $1996 \mathrm{jan} / \mathrm{jul} ; 12(1): 7-30$.

11. Collière MF. Promover a vida: da prática das mulheres de virtude aos cuidados de enfermagem. Lisboa: Sindicato dos Enfermeiros Portugueses; 1989.244p.

12. Leininger M. Culture care diversity and universality: a theory of nursing. New York: National League for Nursing Press;1991.432p.

13. Leininger M. Transcultural nursing: concepts, theories, research \& practices. New York: McGraw-Hill; 1995.727p.

14. Monticelli M. Nascimento como um rito de passagem: abordagem para o cuidado às mulheres e recém-nascidos. Florianópolis (SC): Robe; 1997.235p

15. Saupe R, Brito VH, Giorgi MDM. Utilizando as concepções do educador Paulo Freire no pensar e agir da enfermagem. In: Saupe R, organizadora. Educação em enfermagem: da realidade construída à possibilidade em construção. Florianópolis (SC):UFSC;1998.271p. p.245-72.

16. Candau VM. Nas teias da globalização: cultura e educação. In: Candau VM, organizadora. Sociedade, educação e cultura(s): questões e propostas. Petrópolis(RJ): Vozes; 2002. 284p.p.13-29.

17. Denardin ML. Cuidando e sendo cuidado um modelo cultural de saúde em comunidade rural. In: Gonales RM, Beck CL, Denardin ML. organizadoras. Cenários de cuidado: aplicação de teorias de enfermagem. Santa Maria (RS): Pallotti; 1999.259p.p.159-259.

18. Budó MLD. A prática de cuidados em comunidades rurais e o preparo da enfermeira. Florianópolis (SC): UFSC/PEN; 2002.193p.

19. Polit DF, Hungler B. Fundamentos de pesquisa em enfermagem. $3^{\mathrm{a}}$ ed. Porto Alegre (RS): Artes Médicas; 1995.391p.

20. Ministério da Saúde (BR). Conselho Nacional de Saúde. Diretrizes e normas regulamentadoras da pesquisa envolvendo seres humanos: Resolução n. 196/96. Brasília (DF); 1996. [12 p.] Disponível em: URL: <http://www.ufrgs.br/hcpa/gppg/res19696.htm>. Acessado em: 22 jul 2003.

21. Minayo MCS. O desafio do conhecimento: pesquisa qualitativa em saúde. São Paulo: Hucitec; 1993.269p.

Data de Recebimento: 11/11/2003

Data de Aprovação: 30/04/2004 